\title{
Practice guideline update recommendations summary: Disorders of consciousness
}

\author{
Report of the Guideline Development, Dissemination, and Implementation Subcommittee of the \\ American Academy of Neurology; the American Congress of Rehabilitation Medicine; and the \\ National Institute on Disability, Independent Living, and Rehabilitation Research
}

Joseph T. Giacino, PhD, Douglas I. Katz, MD, Nicholas D. Schiff, MD, John Whyte, MD, PhD, Eric J. Ashman, MD, Stephen Ashwal, MD, Richard Barbano, MD, PhD, Flora M. Hammond, MD, Steven Laureys, MD, PhD, Geoffrey S.F. Ling, MD, Risa Nakase-Richardson, PhD, Ronald T. Seel, PhD, Stuart Yablon, MD, Thomas S.D. Getchius, Gary S. Gronseth, MD, and Melissa J. Armstrong, MD, MSc

Neurology ${ }^{\circledR}$ 2018;91:450-460. doi:10.1212/WNL.0000000000005926

\section{Abstract}

\section{Objective}

To update the 1995 American Academy of Neurology (AAN) practice parameter on persistent vegetative state and the 2002 case definition on minimally conscious state (MCS) and provide care recommendations for patients with prolonged disorders of consciousness (DoC).

\section{Methods}

Recommendations were based on systematic review evidence, related evidence, care principles, and inferences using a modified Delphi consensus process according to the AAN 2011 process manual, as amended.

\section{Recommendations}

Clinicians should identify and treat confounding conditions, optimize arousal, and perform serial standardized assessments to improve diagnostic accuracy in adults and children with prolonged DoC (Level B). Clinicians should counsel families that for adults, MCS (vs vegetative state [VS]/ unresponsive wakefulness syndrome [UWS] ) and traumatic (vs nontraumatic) etiology are associated with more favorable outcomes (Level B). When prognosis is poor, long-term care must be discussed (Level A), acknowledging that prognosis is not universally poor (Level B). Structural MRI, SPECT, and the Coma Recovery Scale-Revised can assist prognostication in adults (Level B); no tests are shown to improve prognostic accuracy in children. Pain always should be assessed and treated (Level B) and evidence supporting treatment approaches discussed (Level B). Clinicians should prescribe amantadine (100-200 mg bid) for adults with traumatic VS/UWS or MCS (4-16 weeks post injury) to hasten functional recovery and reduce disability early in recovery (Level B). Family counseling concerning children should acknowledge that natural history of recovery, prognosis, and treatment are not established (Level B). Recent evidence indicates that the term chronic VS/UWS should replace permanent VS, with duration specified (Level B). Additional recommendations are included.

\author{
Correspondence \\ American Academy of \\ Neurology \\ guidelines@aan.com
}

\section{RELATED ARTICLES}

Comprehensive systematic review update summary: Disorders of consciousness Page 461

Ethical, palliative, and policy considerations in disorders of consciousness Page 471

\section{MORE ONLINE}

\section{ค Podcast}

Dr. Jeff Burns interviews Dr. Joseph Giacino about the updated practice guideline recommendations for patients with disorders of consciousness.

NPub.org/ts 1vao

AMERICAN ACADEMY OF NEUROLOGY

From the Department of Physical Medicine and Rehabilitation (J.T.G.), Spaulding Rehabilitation Hospital and Harvard Medical School; Department of Psychiatry (.T.G.), Massachusetts General Hospital, Boston; Department of Neurology (D.I.K.), Boston University School of Medicine; Braintree Rehabilitation Hospital (D.I.K.), MA; Department of Neurology and Neuroscience (N.D.S.), Weill Cornell Medical College, New York, NY; Moss Rehabilitation Research Institute (J.W.), Elkins Park, PA; Bronson Neuroscience Center (E.J.A.), Bronson Methodist Hospital, Kalamazoo, Ml; Department of Pediatrics, Division of Child Neurology (S.A.), Loma Linda University School of Medicine, CA; Department of Neurology (R.B.), University of Rochester Medical Center, NY; Indiana University Department of Physical Medicine \& Rehabilitation (F.M.H.), University of Indiana School of Medicine, Indianapolis; Coma Science Group-GIGA Research and Department of Neurology (S.L.), Sart Tillman Liège University \& University Hospital, Liège, Belgium; Department of Neurology (G.S.F.L.), Uniformed Services University of Health Sciences, Bethesda; Department of Neurology (G.S.F.L.), Johns Hopkins University, Baltimore, MD; James A. Haley Veterans' Hospital (R.N.-R.), US Department of Veterans Affairs, Tampa, FL; Crawford Research Institute (R.T.S.), Shepherd Center, Atlanta, GA; Center for Rehabilitation Science and Engineering, Department of Physical Medicine \& Rehabilitation (R.T.S.), Virginia Commonwealth University School of Medicine, Richmond; Division of Physical Medicine \& Rehabilitation (S.Y.), University of Mississippi School of Medicine; Brain Injury Program (S.Y.), Methodist Rehabilitation Center, Jackson, MS; Heart Rhythm Society (T.S.D.G.), Washington, DC Department of Neurology (G.S.G.), University of Kansas Medical Center, Kansas City; and Department of Neurology (M.J.A.), University of Florida College of Medicine, Gainesville.

Go to Neurology.org/N for full disclosures. Funding information and disclosures deemed relevant by the authors, if any, are provided at the end of the article.

This research was supported through a memorandum of understanding between the American Academy of Neurology, the American Congress of Rehabilitation Medicine, and the National Institute on Disability and Rehabilitation Research (NIDRR). In 2014, NIDRR was moved from the US Department of Education to the Administration for Community Living of the US Department of Health and Human Services, and was renamed the National Institute on Disability, Independent Living, and Rehabilitation Research (NIDILRR). This article does not reflect the official policy or opinions of NIDILRR or HHS and does not constitute an endorsement by NIDILRR, HHS, or other components of the federal government.

Approved by the AAN Guideline Development, Dissemination, and Implementation Subcommittee on October 21, 2017; by the AAN Practice Committee on April 9, 2018; by the American Congress of Rehabilitation Medicine Board of Governors on April 30, 2018; by the National Institute on Disability, Independent Living, and Rehabilitation Research Review Committee on April 5, 2018; and by the AAN Institute Board of Directors on May 2, 2018.

This practice guideline was endorsed by the American Academy of Physical Medicine and Rehabilitation on April 4, 2018; by the American College of Surgeons Committee on Trauma on July 3, 2018; and by the Child Neurology Society on April 17, 2018.

This special article is published simultaneously in the Archives of Physical Medical Rehabilitation and Neurology. Neurology was responsible for peer review of this article. 


\section{Glossary}

AAN = American Academy of Neurology; ACRM = American Congress of Rehabilitation Medicine; $\mathbf{C I}=$ confidence interval; CRS-R = Coma Recovery Scale-Revised; DoC = disorders of consciousness; DRS = Disability Rating Scale; FDG = fluorodeoxyglucose; MCS = minimally conscious state; TBI = traumatic brain injury; UWS = unresponsive wakefulness syndrome; VS = vegetative state.

This article presents practice guideline recommendations developed by the American Academy of Neurology (AAN), the American Congress of Rehabilitation Medicine (ACRM), and the National Institute on Disability, Independent Living, and Rehabilitation Research (see complete guideline at links. lww.com/WNL/A611). A companion article summarizes systematic review conclusions. ${ }^{1}$

\section{Recommendations}

Unless noted, recommendations apply to individuals with prolonged disorders of consciousness (DoC) (i.e., $\geq 28$ days). Recommendation rationales are presented; tables summarize recommendations for adults (tables 1-3) and children (table 4).

\section{Recommendation 1 rationale}

Our systematic review highlights the complexities of caring for patients with prolonged DoC (i.e., $\geq 28$ days) at every stage. Such patients may be misdiagnosed due to confounding neurologic deficits ${ }^{2}$ or inexperience in examining patients for subtle signs of consciousness. ${ }^{3}$ Accurate diagnosis is important to educate families about patients' level of consciousness and function, inform prognostic counseling, and guide treatment decisions. Knowledge gaps often lead to overestimation or underestimation of prognosis by nonspecialists. ${ }^{4}$ In addition, patients with prolonged $\mathrm{DoC}$ frequently experience significant medical complications that can slow recovery and interfere with treatment interventions. ${ }^{5}$ In view of this risk, patients are likely to have a better chance for recovery if care is provided in a specialized setting managed by clinicians who are knowledgeable about the risks associated with $\mathrm{DoC}$ and are capable of initiating timely treatment. This is supported by findings from a large retrospective trauma registry, which found that cumulative mortality at 3 years postdischarge is significantly lower for patients discharged to home or inpatient rehabilitation facilities than those discharged to skilled nursing facilities, even after adjusting for covariates. ${ }^{6}$ Care for patients with prolonged DoC may benefit from a team of multidisciplinary rehabilitation specialists, including neurologists, psychologists, neuropsychologists, physiatrists, physical therapists, occupational therapists, speech pathologists, nurses, nutritionists, internists, and social workers.

\section{$\oplus$ Supplemental Data}

Full text of guideline at:

NPub.org/m5ii8i

\section{Recommendation 2 rationale}

The range of physical and cognitive impairments experienced by individuals with severe DoC complicates diagnostic accuracy and makes it difficult to distinguish behaviors that are indicative of conscious awareness from those that are random and nonpurposeful. Interpretation of inconsistent behaviors or simple motor responses is particularly challenging. Fluctuations in arousal and response to command further confound the reliability of clinical assessment. ${ }^{7,8}$ Underlying central and peripheral impairments, such as aphasia, neuromuscular abnormalities, and sensory deficits, may also mask conscious awareness. ${ }^{9-11}$ Clinician reliance on nonstandardized procedures, even when the examination is performed by experienced clinicians, ${ }^{2,12,13}$ contributes to diagnostic error, which consistently hovers around $40 \%$. Diagnostic error includes misdiagnosing the locked-in syndrome for vegetative state/unresponsive wakefulness syndrome (VS/UWS) and minimally conscious state (MCS). ${ }^{14,15}$ Accurate diagnosis of the level of consciousness has implications for prognosis and management.

\section{Recommendation 2 a rationale}

In view of the range of clinical challenges to accurate and reliable diagnosis of DoC, standardizing the assessment of patients with DoC can assist in recognizing key diagnostic features that may be missed on ad hoc examinations. ${ }^{12,16}$ The validity and reliability of standardized neurobehavioral assessment scales for diagnosis of DoC subtype have been previously reviewed. ${ }^{17}$ Other techniques such as individualized quantitative behavioral assessment have been useful in distinguishing specific purposeful responses from generalized, nonpurposeful, or reflexive responses. ${ }^{18}$ On the basis of these findings, diagnostic accuracy may be enhanced by using standardized neurobehavioral assessment measures over qualitative bedside examination alone. If standardized assessments are used, those with the highest quality of evidence should be employed. A systematic review performed by ACRM recommended the Coma Recovery Scale-Revised (CRS-R),${ }^{16}$ Wessex Head Injury Matrix,${ }^{19}$ Sensory Modality Assessment and Rehabilitation Technique, ${ }^{20}$ Western NeuroSensory Stimulation Protocol, ${ }^{21}$ Disorders of Consciousness Scale, ${ }^{22}$ and Sensory Stimulation Assessment Measure ${ }^{23}$ for use in clinical practice. ${ }^{17}$

\section{Recommendation $\mathbf{2 b}$ rationale}

While there is insufficient high-quality evidence to recommend the use of serial evaluations to improve diagnostic sensitivity and specificity, because of the inconsistency and variability of behavioral responses that is characteristic of 
Table 1 Recommendation statements ${ }^{\mathrm{a}}$ for overall care and diagnosis for adults with a prolonged disorder of consciousness (DoC)

\begin{tabular}{|c|c|}
\hline $\begin{array}{l}\text { Recommendation } \\
\text { number }\end{array}$ & Recommendation statement and level \\
\hline 1 & $\begin{array}{l}\text { Clinicians should refer patients with DoC who have achieved medical stability to settings staffed by multidisciplinary rehabilitation } \\
\text { teams with specialized training to optimize diagnostic evaluation, prognostication, and subsequent management, including } \\
\text { effective medical monitoring and rehabilitative care (Level B). }\end{array}$ \\
\hline $2 a$ & $\begin{array}{l}\text { Clinicians should use standardized neurobehavioral assessment measures that have been shown to be valid and reliable (such as } \\
\text { those recommended by the ACRM) to improve diagnostic accuracy for the purpose intended (Level B based on importance of } \\
\text { outcomes and feasibility). }\end{array}$ \\
\hline $2 \mathbf{b}$ & $\begin{array}{l}\text { To reduce diagnostic error in individuals with prolonged DoC after brain injury, serial standardized neurobehavioral assessments } \\
\text { should be performed with the interval of reassessment determined by individual clinical circumstances (Level B based on } \\
\text { cogency, feasibility, and cost relative to benefit). }\end{array}$ \\
\hline 2c & $\begin{array}{l}\text { Clinicians should attempt to increase arousal before performing evaluations to assess level of consciousness anytime diminished } \\
\text { arousal is observed or suspected (Level B based on importance of outcomes). }\end{array}$ \\
\hline $2 d$ & $\begin{array}{l}\text { Clinicians should identify and treat conditions that may confound accurate diagnosis of a DoC prior to establishing a final } \\
\text { diagnosis (Level B based on feasibility and cost). }\end{array}$ \\
\hline $2 e$ & $\begin{array}{l}\text { In situations where there is continued ambiguity regarding evidence of conscious awareness despite serial neurobehavioral } \\
\text { assessments, or where confounders to a valid clinical diagnostic assessment are identified, clinicians may use multimodal } \\
\text { evaluations incorporating specialized functional imaging or electrophysiologic studies to assess for evidence of awareness not } \\
\text { identified on neurobehavioral assessment that might prompt consideration of an alternate diagnosis (Level C based on } \\
\text { assessment of benefit relative to harm, feasibility, and cost relative to benefit). }\end{array}$ \\
\hline $2 f$ & $\begin{array}{l}\text { In situations where there is no behavioral evidence of consciousness on clinical examination but functional neuroimaging or } \\
\text { electrophysiologic testing suggests the possibility of preserved conscious awareness, frequent neurobehavioral reevaluations } \\
\text { may be conducted to identify emerging signs of conscious awareness (Level C based on feasibility) and decisions to reduce the } \\
\text { intensity of rehabilitation treatment may be delayed for those individuals receiving active rehabilitation management (Level C } \\
\text { based on variation in patient preferences and cost relative to net benefit), with the length of time over which these are done } \\
\text { determined by an agreement between the treating clinician and the health care proxy given the lack of evidence to provide } \\
\text { guidance. }\end{array}$ \\
\hline
\end{tabular}

Abbreviation: ACRM = American Congress of Rehabilitation Medicine.

${ }^{a}$ Level $\mathrm{A}$ is the strongest recommendation level and is denoted by use of the helping verb must. These recommendations are rare. Level $\mathrm{B}$ corresponds to the helping verb should. Such recommendations are more common, as the requirements are less stringent but are still associated with confidence in the rationale and a favorable benefit-risk profile. Level $C$ corresponds to the helping verb may. These recommendations represent the lowest allowable recommendation level that the American Academy of Neurology considers useful within the scope of clinical practice and can accommodate the highest degree of practice variation.

individuals with prolonged $\mathrm{DoC}$, reliance on a single examination may contribute to greater risk of misdiagnosis. Multiple behavioral evaluations over time may improve diagnostic reliability and accuracy as compared with a single evaluation. Serial evaluations conducted by trained clinicians using a standardized, validated neurobehavioral assessment instrument have the potential to improve the reliability/validity of diagnosis. There are insufficient data to recommend a minimum duration of time for an assessment session or how often serial examinations should be performed. The frequency of serial standardized neurobehavioral examinations should be based on clinical judgment with consideration given to reported changes in arousal and responsiveness, the removal or cessation of diagnostic confounders, and the length of time since the last assessment.

\section{Recommendation $\mathbf{2 c} / 2 \mathrm{~d}$ rationale}

Patients with prolonged DoC may exhibit inconsistent or reduced behavioral responsiveness because of fluctuations in the level of arousal, systemic medical problems, secondary neurologic complications, and other adverse events (e.g., medication side effects). Level of consciousness cannot be assessed accurately during periods of low arousal. In patients who demonstrate fluctuations in wakefulness, efforts should be made to increase arousal level using protocols designed for this purpose (e.g., the CRS-R Arousal Facilitation Protocol) before assessing the level of consciousness. Identifying and treating conditions that impair neurologic functioning may also improve arousal and level of consciousness.

\section{Recommendation $2 \mathrm{e} / 2 \mathrm{f}$ rationale}

Our systematic review identified that some electrophysiologic procedures (EMG thresholds for detecting response to motor commands, EEG reactivity, laser-evoked potential responses, and the Perturbational Complexity Index) possibly have value for distinguishing MCS from VS/UWS, generally to an only mildly important degree. There is insufficient evidence to support or refute the routine clinical use of functional neuroimaging or routine EEG or evoked response studies as clinically useful adjuncts to behavioral evaluations to detect conscious awareness in patients diagnosed with VS/UWS. In addition, functional imaging is not widely available and may not be clinically feasible in large numbers of patients. However, 2 reviewed studies identified fMRI changes in response to a word-counting task and an incorrect-minus-correct activation protocol in patients diagnosed with VS/UWS by the CRS-R (38\%, 95\% confidence interval $[\mathrm{CI}] 14 \%-69 \%$, and $38 \%, 95 \%$ CI $23 \%-56 \%$, 
Table 2 Recommendation statements for prognosis for adults with a prolonged disorder of consciousness (DoC)

Recommendation number

Recommendation statement and level

3

When discussing prognosis with caregivers of patients with a DoC during the first 28 days postinjury, ${ }^{a}$ clinicians must avoid statements that suggest these patients have a universally poor prognosis (Level A).

Clinicians caring for patients with prolonged DoC should perform serial standardized behavioral evaluations to identify trends in the trajectory of recovery that are important for establishing prognosis (Level B).

5

Posttraumatic VS/UWS: Clinicians should perform the DRS at 2-3 months postinjury (Level B) and may assess for the presence of P300 at 2-3 months postinjury (Level C based on feasibility) or assess EEG reactivity at 2-3 months postinjury (Level C based on feasibility) to assist in prognostication regarding 12-month recovery of consciousness for patients in traumatic VS/UWS. Clinicians should perform MRI 6-8 weeks postinjury to assess for corpus callosal lesions, dorsolateral upper brainstem injury, or corona radiata injury in order to assist in prognostication regarding remaining in PVS at 12 months for patients in traumatic VS/UWS (Level B). Clinicians should perform a SPECT scan 1-2 months postinjury to assist in prognostication regarding 12-month recovery of consciousness and degree of disability/recovery for patients in traumatic VS/UWS (Level B). Clinicians may assess for the presence of higher level activation of the auditory association cortex using BOLD fMRI in response to a familiar voice speaking the patient's name to assist in prognostication regarding 12-month (postscan) recovery of consciousness for patients in traumatic VS/ UWS 1-60 months postinjury (Level $C$ based on feasibility, cost).

6

Nontraumatic, postanoxic VS/UWS: Clinicians should perform the CRS-R (Level B) and may assess SEPS (Level C based on feasibility) to assist in prognostication regarding recovery of consciousness at 24 months for patients in nontraumatic postanoxic VS/UWS.

7

Given the frequency of recovery of consciousness after 3 months in patients in nontraumatic VS/UWS, and after 12 months in patients with traumatic VS/UWS (including some cases emerging from MCS), use of the term permanent VS should be discontinued. After these time points, the term chronic VS (UWS) should be applied, accompanied by the duration of the VS/UWS (Level B).

\section{Prognostic counseling recommendations}

8

Clinicians should counsel families that MCS diagnosed within 5 months of injury and traumatic etiology are associated with more favorable outcomes and VS/UWS and nontraumatic DoC etiology are associated with poorer outcomes, but individual outcomes vary and prognosis is not universally poor (Level B based on importance of outcomes).

9

In patients with a prolonged DoC, once a prognosis has been established that indicates a likelihood of severe long-term disability, clinicians must counsel family members to seek assistance in establishing goals of care and completing state-specific forms regarding medical decision-making (e.g., MOLST forms), if not already available, applying for disability benefits, and starting estate, caregiver, and long-term care planning (Level A).

10

When patients enter the chronic phase of VS/UWS (i.e., 3 months after non-TBI and 12 months after TBI), prognostic counseling should be provided that emphasizes the likelihood of permanent severe disability and the need for long-term assistive care (Level B).

Abbreviations: BOLD = blood oxygen level-dependent; CRS-R = Coma Recovery Scale-Revised; DRS = Disability Rating Scale; MCS = minimally conscious state; MOLST = medical orders for life-sustaining treatment; PVS = persistent vegetative state; $\mathrm{SEP}=$ somatosensory evoked potential; $\mathrm{TBI}=$ traumatic brain injury; UWS = unresponsive wakefulness syndrome; VS = vegetative state.

a This is the one recommendation in this guideline pertaining to individuals in a DoC for less than 28 days. While patients with an acute DoC are not the primary population covered by this guideline, the results of the systematic review and review of related evidence showing the potential for long-term recovery in individuals with DoC lasting longer than 28 days also apply when counseling the families of patients who are $<28$ days from injury.

respectively). ${ }^{24,25}$ Research studying DoC populations overlapping with those in this guideline (i.e., cohorts including patients with a DoC for longer than 28 days but not confined exclusively to patients with prolonged DoC) suggests that some individuals without signs of awareness on behavior-based evaluations may have positive findings using other modalities, such as functional MRI, PET scans, or electrophysiologic studies. In 1 study $^{26}$ of patients with VS/ UWS based on standardized neurobehavioral assessment, functional neuroimaging studies $\left({ }^{18} \mathrm{~F}\right.$-fluorodeoxyglucose [FDG] PET, fMRI) performed at various times postinjury demonstrated evidence of brain activity compatible with at least minimal conscious awareness in approximately $32 \%$ of patients scanned using ${ }^{18}$ F-FDG PET or mental imagery fMRI or both $(13 / 41 ; 95 \%$ CI $20 \%-47 \%)$, with ${ }^{18}$ F-FDG PET showing results consistent with MCS in $33 \%$ of patients diagnosed with VS/UWS by the CRS-R (12/36, 95\% CI $20 \%-50 \%)$ and mental imagery fMRI showing results consistent with MCS in 11\% (3/28, 95\% CI 4\%-27\%). When using high-density EEG recordings assessing a combination of low-frequency power, EEG complexity, and information exchange in a population overlapping with that in this guideline, 25 of 75 recordings in patients in VS/UWS (33\%, 95\% CI 24\%-45\%) were classified as suggestive of MCS, with a greater recovery of consciousness in those categorized as MCS than VS/UWS on the EEG (11/50 VS vs $11 / 23 \mathrm{MCS}$, with 2 lost to follow-up; risk difference $26 \%$, $95 \%$ CI $3 \%-47 \%){ }^{27}$

Although multimodal evaluations show promise in increasing sensitivity for detection of conscious awareness, these studies return negative findings in the majority of patients diagnosed with VS/UWS on behavioral assessment, and the exact link between these findings and consciousness remains unclear. Widespread use of multimodal imaging is unlikely to change the diagnosis in most patients diagnosed with VS/UWS. At 
Table 3 Recommendation statements for care and treatment for adults with a prolonged disorder of consciousness (DoC)

\begin{tabular}{ll}
\hline $\begin{array}{l}\text { Recommendation } \\
\text { number }\end{array}$ & Recommendation statement and level \\
\hline $\mathbf{1 1}$ & $\begin{array}{l}\text { Clinicians must identify patient and family preferences early and throughout provision of care to help guide the decision-making } \\
\text { process for persons with prolonged DoC (Level A). }\end{array}$ \\
\hline $\mathbf{1 2}$ & $\begin{array}{l}\text { Clinicians should be vigilant to the medical complications that commonly occur during the first few months after injury among } \\
\text { patients with DoC and, thus, should utilize a systematic assessment approach to facilitate prevention, early identification, and } \\
\text { treatment (Level B). }\end{array}$ \\
\hline $\mathbf{1 3}$ & $\begin{array}{l}\text { Clinicians should assess individuals with a DoC for evidence of pain or suffering and should treat when there is reasonable cause } \\
\text { to suspect that the patient is experiencing pain (Level B), regardless of level of consciousness. Clinicians should counsel families } \\
\text { that there is uncertainty regarding the degree of pain and suffering that may be experienced by patients with a DoC (Level B). }\end{array}$ \\
\hline $\mathbf{1 4}$ & $\begin{array}{l}\text { Clinicians caring for patients with traumatic VS/UWS or MCS who are between } 4 \text { and 16 weeks postinjury should prescribe } \\
\text { amantadine } 100-200 \text { mg twice daily to hasten functional recovery and reduce degree of disability in the early stages of recovery } \\
\text { after determining there are no medical contraindications or other case-specific risks for use (Level B). }\end{array}$ \\
\hline $\mathbf{1 5}$ & $\begin{array}{l}\text { Clinicians should counsel families about the limitations of existing evidence concerning treatment effectiveness and the potential } \\
\text { risks and harms associated with interventions that lack evidentiary support (Level B). When discussing nonvalidated treatments, } \\
\text { clinicians should provide evidence-based information regarding the projected benefits and risks of a particular treatment and the } \\
\text { level of uncertainty associated with the proposed intervention, keeping in mind that families and caregivers are often in distress } \\
\text { and vulnerable (Level B). Clinicians should counsel families that, in many cases, it is impossible to discern whether improvements } \\
\text { observed early in the course of recovery were caused by a specific intervention or spontaneous recovery (Level B). }\end{array}$
\end{tabular}

Abbreviations: MCS = minimally conscious state; UWS = unresponsive wakefulness syndrome; VS = vegetative state.

the same time, injury sequelae (such as severe hypertonus) may confound behavioral assessment and compromise diagnostic accuracy. In addition, diagnostic findings may remain ambiguous despite serial assessment due to the inconsistency or subtlety of the behavioral evidence. The largest functional neuroimaging study conducted to date in patients with DoC reported that ambiguous or erroneous findings clouded clinical diagnosis in 33 of $126(27 \%)$ cases. $^{26}$

\section{Recommendation 3 rationale}

In patients with severe traumatic brain injury (TBI), many of whom have a DoC, one study found that hospital mortality was $32 \%$, with $70 \%$ of those deaths associated with the withdrawal of life-sustaining therapy. ${ }^{4}$ Withdrawal of lifesustaining therapy was more closely associated with the facility where care was provided than with baseline characteristics, including age, sex, pupillary reactivity, and Glasgow Coma Scale motor score. ${ }^{4}$ While withdrawal of life-sustaining therapy was high, this systematic review identified that individuals with a DoC lasting longer than 1 month postinjury may still attain functionally significant recovery after 1 year postinjury. Additional research shows that patients with prolonged DoC can achieve at least some degree of functional independence during long-term follow-up. For example, one study found that approximately $20 \%$ of patients with a traumatic VS/UWS DoC admitted to inpatient rehabilitation were judged to be functionally independent and capable of returning to employment at 1,2 , or 5 years. ${ }^{28}$ Another longitudinal study including patients with traumatic and nontraumatic DoC reported that almost half of the sample recovered to at least daytime independence at home and 22\% returned to school or work. ${ }^{29}$ While these studies may not be fully generalizable, they suggest the potential for recovery in this population, which has implications for prognostic discussions.

\section{Recommendation 4 rationale}

The natural history of DoC is not well-defined, particularly for populations with nontraumatic brain injury, and diagnosis and prognosis can be challenging. Individuals with DoC can fluctuate between different diagnostic categories such as VS and MCS. Fluctuation is particularly common early in the course of recovery, ${ }^{30}$ and one study suggests a $30 \%$ probability of observing behaviors suggestive of MCS in patients diagnosed with

Table 4 Recommendation statements for care for children with a prolonged disorder of consciousness (DoC)

Recommendation

number

Recommendation statement and level

16

Clinicians should treat confounding conditions, increase arousal prior to diagnostic assessments, use valid and reliable standardized behavioral assessments (particularly those targeting pediatric populations), and conduct serial assessments to improve diagnostic accuracy in children with prolonged DoC (Level B).

17

Clinicians should counsel families that the natural history and prognosis of children with prolonged DoC is not well-defined and that there are no current evaluations established to improve prognostic accuracy in this population (Level B).

18

Clinicians should counsel families that there are no established therapies for children with a prolonged DoC (Level B). 
VS/UWS when assessments are conducted in the morning. ${ }^{7}$ Patients with VS may also emerge to MCS over time. MCS is probably associated with a better prognosis than VS. Serial examinations, already suggested to improve diagnostic accuracy, may also aid prognosis in view of the relationship between diagnosis and prognosis.

\section{Recommendation 5 rationale}

In patients diagnosed with prolonged traumatic VS/UWS, Disability Rating Scale (DRS) scores $<26$ at 2-3 months postinjury, a detectable $\mathrm{P} 300$ at $2-3$ months postinjury, a reactive EEG at $2-3$ months postinjury, and higher-level activation of the auditory association cortex using blood oxygen level-dependent fMRI in response to a familiar voice speaking the patient's name probably have prognostic utility, suggesting an increased chance of recovering consciousness within 12 months. A normal SPECT scan at 1-2 months postinjury, lower DRS scores in general 2-3 months postinjury, and a detectable P300 2-3 months postinjury after controlling for DRS and EEG reactivity are possibly associated with either an increased likelihood of recovery of consciousness or a more favorable outcome, while MRI performed 6-8 weeks postinjury showing corpus callosal lesions, dorsolateral upper brainstem injury, or corona radiata injury are possibly associated with a worse prognosis at 12 months.

\section{Recommendation 6 rationale}

In patients diagnosed with nontraumatic postanoxic VS/ UWS, it is highly probable that CRS-R scores of $\geq 6$ obtained more than 1 month after onset and the presence of somatosensory evoked potentials from bilateral median nerve stimulation each have prognostic utility as independent predictors of recovery, suggesting an increased likelihood of recovery of responsiveness by 24 months postinjury.

\section{Recommendation 7 rationale}

The 1994 AAN Multi-Society Task Force defined VS as permanent 3 months after a nontraumatic injury leading to VS and 12 months following a traumatic injury, acknowledging that unexpected recoveries will occur after these times but that these cases will be rare and typically associated with severe disability. ${ }^{31}$ A reanalysis of the Task Force data concluded that the estimated rates of late recovery for traumatic and nontraumatic VS were unreliable due to inconsistent follow-up (only 27 cases were available with follow-up after 12 months), unreliable reporting (in some cases, follow-up was obtained through "personal communications"), and questionable diagnostic accuracy. ${ }^{32}$ Relying only on the portion of the Task Force dataset that was extracted from the Traumatic Coma Data Bank ${ }^{33}$ (which appropriately defined VS and reported findings on 25 cases followed after 12 months), 6 patients (14\%) recovered consciousness between 1 and 3 years postinjury. This recovery rate is substantially higher than the $1.6 \%$ reported in the Task Force Report and raised questions about the appropriateness of the term permanent VS.
In the current systematic review, no study evaluated the prognosis of patients with traumatic VS/UWS after 12 months of injury. One Class II study mixing patients with traumatic and nontraumatic VS/UWS found that none of these patients in VS/UWS 12 months after onset improved when assessed at $2,3,4$, and 5 years postinjury ( 1 lost to follow-up, 9 died, and 2 remained in VS/UWS), but due to the small sample size, CIs for the possibility of improving were wide $(0 \%, 95 \%$ CI $0 \%-24 \%){ }^{34}$

Recent studies suggest that some patients with prolonged nontraumatic VS/UWS may experience ongoing recovery after 3 months. Meta-analyses performed in this systematic review found it is possible that $17 \%$ (95\% CI 5\%-30\%) will recover consciousness (emerge from VS/UWS) at 6 months. After 6 months, it is possible that an estimated 7.5\% (95\% CI $0 \%-24 \%)$ may recover consciousness. In one study of prolonged anoxic vegetative state included in the systematic review, of the 9 of 43 recovering responsiveness, 2 recovered between 3 and 6 months, 3 recovered at 6-12 months, and 4 recovered at 12-24 months. Of the 2 individuals emerging from MCS, 1 patient recovered consciousness at 16 months and emerged from MCS at 18 months and the other recovered consciousness at 22 months and emerged from MCS at 25 months; both remained severely disabled. Of 41 patients who remained in VS/UWS at 6 months, 7 additional patients recovered consciousness before 24 months (17\%, 95\% CI $9 \%-31 \%) .{ }^{35}$ The natural history of nontraumatic VS/UWS is likely tied to the underlying etiology, with nontraumatic VS/ UWS related to a specific insult (e.g., anoxic injury, ischemia) different from that relating to ongoing neurodegeneration.

Additional evidence suggests that late transition to MCS from VS/UWS may occur in as many as $20 \%$ of patients who meet permanence criteria. One study followed 50 patients who remained unconscious for a mean of 11.1 ( \pm 4.8$)$ months after traumatic or nontraumatic brain injury and reported that 10 patients ( 7 traumatic, 3 nontraumatic) recovered consciousness between 14 and 28 months postonset. ${ }^{36}$ A second study followed 108 patients with TBI across a 5-year interval, all of whom failed to recover command-following during the course of inpatient rehabilitation. Among the 17 patients who were still unable to follow commands at 12 months postonset, $8(47.0 \%)$ regained this ability between 1 and 5 years postinjury. $^{28}$

Although the majority of patients who remain in VS/UWS across the first 3 (after nontraumatic) and 12 months (after traumatic) postinjury will remain in this condition permanently, a substantial minority will recover consciousness beyond this time frame. While most of these patients will be left with severe disability, functional outcome ratings indicate that some will regain the ability to communicate reliably, perform self-care activities, and interact socially. ${ }^{37}$

In view of these findings, continued use of the term permanent VS is not justified. Use of this term implies irreversibility, 
which is not supported by the current research and has implications for family counseling, decision-making, and the ethics of the field. The guideline panel suggests that the term permanent VS be replaced by the term chronic VS to indicate the stability of the condition (in keeping with other diseases that have a chronic phase). This should be accompanied by a description of the current duration of the VS/UWS, as evidence supports a decreasing likelihood of recovery with longer duration of unresponsiveness. Because most patients with late recovery of consciousness will remain fully or partially dependent upon others for activities of daily living, prognostic counseling should emphasize the need for longterm care and specify the type of supportive care required.

\section{Recommendation 8 rationale}

Systematic review evidence showed that in patients with prolonged DoC, those diagnosed with MCS within the first 5 months of injury have a more favorable long-term prognosis for functional recovery than those diagnosed with VS/UWS. Long-term prognosis is also more favorable in patients in MCS who have sustained traumatic vs nontraumatic brain injury. ${ }^{38}$ The evidence reviewed does not clearly support or refute age and time postinjury as prognostic features.

As described in the rationale for recommendation 3 above, evidence from the systematic review identified that individuals with a DoC at 1 month postinjury may still attain functionally significant recovery after 1 year postinjury, with additional longitudinal studies showing that approximately $20 \%$ of patients recover to the level where they could return to work or school. ${ }^{28,29}$

\section{Recommendation 9 rationale}

Patients with prolonged DoC may have a prolonged recovery over months to years, and many will remain severely disabled. Employment and personal finances in the short term and the long term will be significantly affected, and these effects will have implications for family members. Patients and families benefit from planning in advance for an expected prolonged recovery.

\section{Recommendation 10 rationale}

See rationale for recommendation 7 .

\section{Recommendation 11 rationale}

Preexpressed wishes of patients with prolonged DoC and values of families of persons with prolonged $\mathrm{DoC}$ can be highly variable. Values may also change over the course of illness. Personal values should be identified early and need to be reassessed over time when making decisions regarding care for individuals with prolonged DoC.

\section{Recommendation 12 rationale}

Complication rates are high in patients with prolonged DoC and negatively affect morbidity and mortality. ${ }^{5,39,40, \mathrm{e} 1}$ It is important that clinicians remain vigilant to medical complications in the short term to facilitate their early identification and to help optimize long-term outcomes. The most common complications in patients with prolonged DoC include agitation/aggression, hypertonia, sleep disturbance, and urinary tract infections. ${ }^{37}$ Other, more severe complications, such as hydrocephalus, pneumonia, and paroxysmal sympathetic hyperactivity, can disrupt rehabilitation efforts, as they often require rehospitalization. ${ }^{37}$ Strategies for early detection and rapid management of complications include daily physician rounds, 24-hour specialty physician coverage, on-site availability of diagnostic resources, and timely access to specialty consultations. ${ }^{37}$

\section{Recommendation 13 rationale}

The potential to experience pain and suffering is an issue frequently raised with respect to treatment, ethical, and legal questions in individuals with DoC. Some studies using functional imaging indicate that brain activation in networks supporting pain perception is lower in patients diagnosed with VS compared with those in MCS and conscious controls, suggesting that patients in VS lack capacity for full pain awareness. ${ }^{\text {e2,e3 }}$ Other studies suggest that the relationship between level of consciousness and pain perception is unclear. ${ }^{\text {e4,es }}$ Accurate assessment of pain and suffering in individuals with DoC is limited by challenges in accurately diagnosing pain due to the level of consciousness and conflicting evidence regarding the potential of patients in VS or MCS to experience pain and suffering. Clinicians should be cautious in making definitive conclusions about pain and suffering in individuals with DoC.

\section{Recommendation 14 rationale}

Amantadine (100-200 mg twice daily), when administered over a period of 4 weeks in patients between 16 and 65 years old with traumatic DoC who are between 4 and 16 weeks of injury, probably hastens functional recovery in the early stages. Faster recovery reduces the burden of disability, lessens health care costs, and minimizes psychosocial stressors in patients and caregivers.

\section{Recommendation 15 rationale}

Most therapies proposed for treating patients with DoC (e.g., hyperbaric oxygen, nutraceuticals, stem cell therapies, primrose oil) have insufficient evidence to support or refute their use, and many have associated risks. Families may pursue these treatments in the absence of evidence because they are desperate for ways to help their loved one and interventions supported by high-quality evidence are sparse. Counseling families about treatment effectiveness is complicated by the difficulties inherent in determining whether improvements observed early in the course of recovery are related to interventions or due to spontaneous recovery.

\section{Recommendation 16 rationale}

No evidence was identified regarding the diagnosis of children with prolonged DoC. In the absence of pediatric-specific evidence, it is reasonable to apply the diagnostic recommendations for adult populations that address the treatment of confounding conditions to improve diagnosis, the 
importance of increasing arousal prior to diagnostic assessments, using valid and reliable standardized behavioral assessments, and conducting serial assessments to children with DoC.

\section{Recommendation 17 rationale}

The natural history of DoC in children is not well-defined. In children with prolonged DoC, traumatic etiology is possibly associated with a better chance of recovery, as is the absence of posttraumatic autonomic dysfunction. Posttraumatic hyperthermia may be associated with a worse outcome. No other evidence was identified.

\section{Recommendation 18 rationale}

No identified therapeutic studies enrolled pediatric populations. The only therapeutic intervention shown to have efficacy in adults (16-65 years) is amantadine. A retrospective case-controlled study of amantadine use in patients with TBI reported that $9 \%$ of children taking this treatment had side effects, but methodologic concerns limit therapeutic conclusions from this study.

\section{Author contributions}

Dr. Giacino: study concept and design, acquisition, analysis, and interpretation of data, drafting/revising the manuscript, critical revision of the manuscript for important intellectual content, study supervision. Dr. Katz: study concept and design, acquisition, analysis, and interpretation of data, drafting/ revising the manuscript, critical revision of the manuscript for important intellectual content. Dr. Schiff: study concept and design, acquisition, analysis, and interpretation of data, drafting/revising the manuscript, critical revision of the manuscript for important intellectual content. Dr. Whyte: study concept and design, acquisition, analysis, and interpretation of data, drafting/revising the manuscript, critical revision of the manuscript for important intellectual content. Dr. Ashman: acquisition, analysis, and interpretation of data, critical revision of the manuscript for important intellectual content. Dr. Ashwal: study concept and design, acquisition, analysis, and interpretation of data, drafting/revising the manuscript, critical revision of the manuscript for important intellectual content. Dr. Barbano: acquisition, analysis, and interpretation of data, drafting/revising the manuscript, critical revision of the manuscript for important intellectual content, study supervision. Dr. Hammond: acquisition, analysis, and interpretation of data, drafting/revising the manuscript, critical revision of the manuscript for important intellectual content. Dr. Laureys: acquisition, analysis, and interpretation of data, drafting/revising the manuscript, critical revision of the manuscript for important intellectual content. Dr. Ling: acquisition, analysis, and interpretation of data, drafting/revising the manuscript, critical revision of the manuscript for important intellectual content. Dr. NakaseRichardson: acquisition, analysis, and interpretation of data, drafting/revising the manuscript, critical revision of the manuscript for important intellectual content. Dr. Seel: acquisition, analysis, and interpretation of data, drafting/ revising the manuscript, critical revision of the manuscript for important intellectual content. Dr. Yablon: acquisition, analysis, and interpretation of data, drafting/revising the manuscript, critical revision of the manuscript for important intellectual content. T. Getchius: acquisition, analysis, and interpretation of data. Dr. Gronseth: acquisition, analysis, and interpretation of data, drafting/revising the manuscript, critical revision of the manuscript for important intellectual content. Dr. Armstrong: acquisition, analysis, and interpretation of data, drafting/revising the manuscript, critical revision of the manuscript for important intellectual content, study supervision.

\section{Study funding}

This practice guideline was funded by the American Academy of Neurology (AAN), the American Congress of Rehabilitation Medicine, and the National Institute on Disability, Independent Living, and Rehabilitation Research. Authors who serve or served as AAN subcommittee members (E.J.A., S.A., R.B., G.S.G.) or as methodologists (M.J.A., G.S.G.), or who were AAN staff members (T.S.D.G.), were reimbursed by the AAN for expenses related to travel to subcommittee meetings where drafts of manuscripts were reviewed.

\section{Disclosure}

J. Giacino has received funding for travel from the US Department of Defense for a meeting related to the TBI Endpoint Development Project; from the National Institute on Neurological Disorders and Stroke (NINDS) of the NIH for a meeting related to the Transforming Research and Clinical Knowledge in Traumatic Brain Injury study; from the National Institute on Disability, Independent Living, and Rehabilitation Research (NIDILRR) for the Traumatic Brain Injury Model Systems Project Directors meeting; from the American Academy of Physical Medicine and Rehabilitation, the One Mind Foundation, and the James S. McDonnell Foundation for a meeting related to the Recovery of Consciousness After Severe Brain Injury study; from the Barbara Epstein Foundation; and from the International Brain Injury Association; has received a cash donation from the Epstein Foundation for a hospital clinical program that he directs and for serving on a team that provided clinical consultation services to an overseas patient who sustained severe brain injury; has served as an editor for the Journal of Head Trauma Rehabilitation; has received honoraria from the One Mind Foundation, Holy Cross Hospital (Surrey, UK), HealthSouth Braintree Hospital, Western Michigan Brain Injury Network, George Washington University Medical School, Association of Academic Physiatrists, Mayo Clinic, Kennedy-Krieger Institute, and Magill's Medical Guide; performs clinical procedures as $10 \%$ of his clinical effort in his role as Director of Spaulding Rehabilitation Network Disorders of Consciousness Program and neuroimaging as a principal investigator on 2 neuroimaging studies for $30 \%$ of his research effort; received financial support from the NIH NINDS for Central Thalamic Stimulation for Traumatic Brain Injury, US Department of 
Defense for TBI Endpoint Development Project, the Huperzine A for the Treatment of Cognitive, Mood and Functional Deficits After Moderate and Severe TBI study, the Injury and Traumatic Stress (INTRuST) Consortium Neuroimaging Acquisition and Archival study, the NIDILRR for the Spaulding Harvard-Traumatic Brain Injury Model System and for Multicenter Evaluation of Memory Remediation after Traumatic Brain Injury with Donepezil, the NINDS for Transforming Research and Clinical Knowledge in Traumatic Brain Injury study, James S. McDonnell Foundation for Study of Recovery of Consciousness After Severe Brain Injury, Barbara Epstein Foundation, and the Spaulding Rehabilitation Hospital Department of Physical Medicine and Rehabilitation; and has acted as a witness with regard to a legal proceeding. D. Katz has received royalties from Demos for Brain Injury Medicine, 2013, and from Lash Publications; has received honoraria for speaking at HealthSouth/Encompass Health Medical Directors' Conference, various grand rounds on topics related to DoC, including Harvard Longwood Neurology, Providence VA Hospital, Tufts Medical Center, Baystate Medical Center, and University of Massachusetts Medical Center, and for service as Chair, External Scientific Advisory Board, VA Rehabilitation Research and Development TBI Center of Excellence, Boston; has given expert testimony in several legal cases involving patients with DoC after brain injury; has received travel support for talks and conferences on DoC from organizations, including World Federation of Neurorehabilitation, International Brain Injury Association, and Moody Foundation/Galveston Brain Injury Conference; received a stipend as medical director of the Acquired Brain Injury Program at Braintree Rehabilitation Hospital from HealthSouth; received compensation for less than $10 \%$ of his clinical effort for consultations on patients with DoC; and received support from efforts on NIDILRRfunded projects on DoC. N. Schiff serves on an advisory board for Intelect Medical Inc. and Enspire DBS, Inc. (Cleveland); is listed as inventor for multiple patents held by Cornell University; receives royalties for Plum and Posner's Stupor and Coma, Oxford University Press; and holds $0.25 \%$ stock option in Enspire DBS, Inc. (no current value). J. Whyte served on a scientific advisory board for INTRuST; received funding for travel and honoraria from several noncommercial institutions for academic lectures; performs diagnostic behavioral assessments of patients with DoC as $10 \%$ of his clinical effort; received financial support from the NIH, the NIDILRR, and the Patient-Centered Outcomes Research Institute; and has given expert testimony with regard to a patient with DoC. E. Ashman served as Level of Evidence associate editor for Neurology ${ }^{\circledR}$ from 2011 to 2013; provided uncompensated medical-legal reviews for US Air Force legal proceedings as part of his active-duty responsibilities until 2012; received funding from the AAN to attend Guideline Development, Dissemination, and Implementation Subcommittee meetings as a subcommittee member and as an ex officio member through January 2018; and has been selected to serve on the editorial board of Neurology: Clinical Practice starting April 2018. S. Ashwal served on a medical advisory board for the
Tuberous Sclerosis Association; serves as chief of the Division of Child Neurology, Department of Pediatrics, Loma Linda University School of Medicine; receives royalties for Pediatric Neurology: Principles and Practice, 6th ed.; and received financial support from the NIH NINDS for research on pediatric traumatic brain injury and for use of advanced imaging for detecting neural stem cell migration after neonatal HII in a rat pup model. R. Barbano has served as the associate editor for Neurology: Clinical Practice; has received compensation from law firms and insurance companies for independent medical records reviews and examinations; holds stock options from Visual Dx, Inc.; served on a speakers bureau for Allergan Inc.; and receives research support from the NIH Office of Rare Diseases Research via the Dystonia Coalition, unrelated to the content of this guideline. His spouse has received an NIH grant unrelated to the content of this guideline. F. Hammond is a member of the ACRM Disorders of Consciousness Task Force; served on the US Department of Defence INTRuST Scientific Advisory Council and Avanir Prism II Study Steering Committee; has received royalties from Demos Publishing and Lash Publishing; has received financial support for research from the NIDILRR; holds stock in AbbVie Inc., Amgen Inc., AstraZeneca Plc, Edwards Lifesciences, GW Pharmaceuticals Plc, Intuitive Surgical Inc., Konink Logistics Inc., Merck \& Co. Inc., Pfizer Inc., Sanofi, Thermo Fisher Scientific Inc., UnitedHealth Group, and Zoetis Inc.; and has given legal testimony and acted as legal consultant in legal proceedings on the care needs of individuals with brain injury. S. Laureys performs $\mathrm{AMRI}$, PET, and EEG as $20 \%$ of his clinical effort; received funding from noncommercial institutions such as Belgium's National Fund for Scientific Research, European Commission, Collaborative European NeuroTrauma Effectiveness Research in TBI Project, Human Brain Project, James McDonnell Foundation, European Space Agency, "Fondazione Europea di Ricerca Biomedica," BIAL Foundation, Belspo, Wallonia-Brussels Federation Concerted Research Action, and Mind Science Foundation; has served as an editor for Progress in Brain Research and Current Opinion in Neurology; is a member of the Belgian Advisory Committee on Bioethics and Belgian Brain Council and board member of the International Brain Injury Association; elected delegate of the European Academy of Neurology; President of the Association for the Scientific Study of Consciousness and chair of the World Federation of Neurology Applied Research Group on Coma and Disorders of Consciousness; receives royalties for The Neurology of Consciousness, Elsevier, 2015; has given expert testimony with regard to legal cases in Belgium and the Netherlands; and has prepared an affidavit and acted as a witness for legal proceedings in Belgium. G. Ling has served on scientific advisory boards for the NIH National Center for Advancing Translational Sciences (NCATS), the Veterans Administration National Research Advisory Council, Biogen, Facebook B8, KnoLimits, LLC, NED Biosystems, and Camden Partners; served on the board of directors of BioElectron Technologies Corporation (aba Edison Pharmaceuticals); received funding for travel from NIH NCATS, Facebook B8, Edison 
Pharmaceuticals, KnoLimits, LLC, and Camden Partners; served as a guest editor for Seminars in Neurology and Experimental Neurology; holds a patent (U.S. Patent 7, 195, 595-B2) with Campbell, M., for a method and apparatus used for monitoring the efficacy of fluid resuscitation; received honoraria from Medtronics, National Defense University (Japan), Sanofi Aventis, Science Teachers, and University of Panama; has been employed by SunQLLC, DrsGSLing, and Center for Brain Health; and holds stock in BioElectron Technologies Corporation (aba Edison Pharmaceuticals), Host Response, NED Biosystems, Camden Partners, Pfizer, and Merck. R. Nakase-Richardson has received financial compensation for travel for speaking at the University of Mississippi Medical Center, New York University, Mayo Clinic, and University of Alabama, Birmingham; and has received research support from General Dynamics Health Solutions from the Defense and Veterans Brain Injury Center within the Defense Health Agency, US Department of Veterans Affairs Health Services Research and Development, Department of Veterans Affairs Rehabilitation Research and Development, and PatientCentered Outcomes Research Institute. R. Seel has served as both a member and the Chair of the ACRM Disorders of Consciousness Task Force and the ACRM Evidence and Practice Committee; served as an editor for the Journal of Head Trauma Rehabilitation; holds a patent on an electronic driving coach; receives publishing royalties from Pearson; received honoraria for several university-based talks; received payment as a grant reviewer for the Department of Defense Congressionally Directed Medical Research Programs and US Department of Veterans Affairs Rehabilitation Research and Development Service; and has received research funding from the NIDILRR, the NIH, the Centers for Disease Control and Prevention, the Craig H. Neilsen Foundation, and the Shepherd Center Foundation. S. Yablon has served on scientific advisory boards for Allergan Inc., Flowonix Medical Inc., Ipsen Pharma, Medtronic Inc., and Merz Pharmaceuticals $\mathrm{GmbH}$; received travel-related funding from Allergan Inc., Ipsen Pharma, Medtronic Inc., and Merz Pharmaceuticals $\mathrm{GmbH}$; served as associate editor for the journal $P M \leftrightarrow R$ and on the editorial advisory board for the Baylor University Medical Center Proceedings; has received honoraria for presentations given during scientific meetings sponsored or cosponsored by Allergan Inc. and Merz Pharmaceuticals $\mathrm{GmbH}$; performs botulinum neurotoxin procedures for treatment of focal spastic hypertonia ( $<10 \%$ of clinical effort); has received financial research support from Medtronic Inc. and research support from the NIDILRR; and has given expert testimony and acted as legal consultant in legal proceedings. T. Getchius has received financial compensation for travel to speak at the University of Louisville mTBI conference and the New York Academy of Medicine E-GAPPS conferences; has been serving as the vice-chair of the Council of Medical Specialty Societies Clinical Practice Guideline Component Group from November 2013 to present; has received research support (all monies directed to the AAN) from the Centers for Disease Control and Prevention for a grant for muscular dystrophy guideline development, dissemination, and implementation; and is a past employee of the AAN. G. Gronseth serves on the Neurology Now editorial advisory board and receives financial support for serving as chief evidence-based methodologist for the AAN. M. Armstrong serves on the Level of Evidence editorial board for Neurology (but is not compensated financially) and serves as an evidence-based medicine methodologist for the AAN. Go to Neurology.org/ $\mathrm{N}$ for full disclosures.

\section{Disclaimer}

Clinical practice guidelines, practice advisories, systematic reviews, and other guidance published by the American Academy of Neurology (AAN) and its affiliates and the American Congress of Rehabilitation Medicine (ACRM) are assessments of current scientific and clinical information provided as an educational service. The information (1) should not be considered inclusive of all proper treatments, methods of care, or as a statement of the standard of care; (2) is not continually updated and may not reflect the most recent evidence (new evidence may emerge between the time information is developed and when it is published or read); (3) addresses only the questions specifically identified; (4) does not mandate any particular course of medical care; and (5) is not intended to substitute for the independent professional judgment of the treating provider, as the information does not account for individual variation among patients. In all cases, the selected course of action should be considered by the treating provider in the context of treating the individual patient. Use of the information is voluntary. The AAN and ACRM specifically disclaim any warranties of merchantability or fitness for a particular use or purpose. The AAN and ACRM assume no responsibility for any injury or damage to persons or property arising out of or related to any use of this information or for any errors or omissions. This document does not reflect the official policy or opinions of the National Institute on Disability, Independent Living, and Rehabilitation Research (NIDILRR) or the US Health and Human Services Department (HSS) and does not constitute an endorsement by NIDILRR, HHS, or other components of the federal government.

\section{Conflict of interest}

The American Academy of Neurology (AAN) and the American Congress of Rehabilitation Medicine (ACRM) are committed to producing independent, critical, and truthful clinical practice guidelines (CPGs). Significant efforts are made to minimize the potential for conflicts of interest to influence the recommendations of this CPG. To the extent possible, the AAN and the ACRM keep separate those who have a financial stake in the success or failure of the products appraised in the CPGs and the developers of the guidelines. Conflict of interest forms were obtained from all authors and reviewed by an oversight committee prior to project initiation. The AAN and the ACRM limit the participation of authors with substantial conflicts of interest. The AAN and ACRM forbid commercial participation in, or funding of, guideline projects. Drafts of the 
guideline have been reviewed by at least 3 AAN committees, at least 2 ACRM committees, a network of neurologists, Neurology peer reviewers, and representatives from related fields. The AAN Guideline Author Conflict of Interest Policy can be viewed at aan.com. For complete information on this process, access the 2011 AAN process manual, as amended (aan.com/ Guidelines/Home/Development).

Received December 12, 2017. Accepted in final form May 22, 2018.

\section{References}

1. Giacino JT, Katz DI, Schiff ND, et al; for the Guideline Development, Dissemination, and Implementation Subcommittee of the American Academy of Neurology. Comprehensive systematic review update summary: disorders of consciousness: report of the Guideline Development, Dissemination, and Implementation Subcommittee of the American Academy of Neurology; the American Congress of Rehabilitation Medicine; and the National Institute on Disability, Independent Living, and Rehabilitation Research. Neurology 2018;91:461-470.

2. Andrews K, Murphy L, Munday R, Littlewood C. Misdiagnosis of the vegetative state: retrospective study in a rehabilitation unit. BMJ 1996;313:13-16.

3. Lovstad M, Froslie KF, Giacino JT, Skandsen T, Anke A, Schanke AK. Reliability and diagnostic characteristics of the JFK Coma Recovery Scale-revised: exploring the influence of rater's level of experience. J Head Trauma Rehabil 2010;25:349-356.

4. Turgeon AF, Lauzier F, Simard JF, et al; for the Canadian Critical Care Trials Group. Mortality associated with withdrawal of life-sustaining therapy for patients with severe traumatic brain injury: a Canadian multicentre cohort study. CMAJ 2011;183: 1581-1588.

5. Whyte J, Nordenbo AM, Kalmar K, et al. Medical complications during inpatient rehabilitation among patients with traumatic disorders of consciousness. Arch Phys Med Rehabil 2013;94:1877-1883.

6. Davidson GH, Hamlat CA, Rivara FP, Koepsell TD, Jurkovich GJ, Arbabi S. Longterm survival of adult trauma patients. JAMA 2011;305:1001-1007.

7. Cortese MD, Riganello F, Arcuri F, et al. Coma Recovery Scale-R: variability in the disorder of consciousness. BMC Neurol 2015;15:186.

8. Candelieri A, Cortese MD, Dolce G, Riganello F, Sannita WG. Visual pursuit: within-day variability in the severe disorder of consciousness. J Neurotrauma 2011;28:2013-2017.

9. Bardin JC, Fins JJ, Katz DI, et al. Dissociations between behavioural and functional magnetic resonance imaging-based evaluations of cognitive function after brain injury. Brain 2011;134:769-782.

10. Schnakers C, Zasler N. Assessment and management of pain in patients with disorders of consciousness. PM R 2015;7:S270-S277.

11. Majerus S, Gill-Thwaites H, Andrews K, Laureys S. Behavioral evaluation of consciousness in severe brain damage. Prog Brain Res 2005;150:397-413.

12. Schnakers C, Vanhaudenhuyse A, Giacino J, et al. Diagnostic accuracy of the vegetative and minimally conscious state: clinical consensus versus standardized neurobehavioral assessment. BMC Neurol 2009;9:35.

13. Childs NL, Mercer WN, Childs HW. Accuracy of diagnosis of persistent vegetative state. Neurology 1993;43:1465-1467.

14. Smart CM, Giacino JT, Cullen T, et al. A case of locked-in syndrome complicated by central deafness. Nat Clin Pract Neurol 2008;4:448-453.

15. Laureys S, Pellas F, Van Eeckhout P, et al. The locked-in syndrome: what is it like to be conscious but paralyzed and voiceless? Prog Brain Res 2005;150:495-511.

16. Giacino JT, Kalmar K, Whyte J. The JFK Coma Recovery Scale-Revised: measurement characteristics and diagnostic utility. Arch Phys Med Rehabil 2004;85: 2020-2029.

17. Seel RT, Sherer M, Whyte J, et al. Assessment scales for disorders of consciousness: evidence-based recommendations for clinical practice and research. Arch Phys Med Rehabil 2010;91:1795-1813.
18. Whyte J, DiPasquale MC, Vaccaro M. Assessment of command-following in minimally conscious brain injured patients. Arch Phys Med Rehabil 1999;80:653-660.

19. Shiel A, Horn SA, Wilson BA, Watson MJ, Campbell MJ, McLellan DL. The Wessex Head Injury Matrix (WHIM) main scale: a preliminary report on a scale to assess and monitor patient recovery after severe head injury. Clin Rehabil 2000;14:408-416.

20. Gill-Thwaites H, Munday R. The Sensory Modality Assessment Rehabilitation Technique (SMART): a valid and reliable assessment for the vegetative and minimally conscious state patient. Brain Inj 2004;18:1255-1269.

21. Ansell BJ, Keenan JE. The Western Neuro Sensory Stimulation Profile: a tool for assessing slow-to-recover head-injured patients. Arch Phys Med Rehabil 1989;70: 104-108.

22. Pape TL, Heinemann AW, Kelly JP, Hurder AG, Lundgren S. A measure of neurobehavioral functioning after coma. Part I: theory, reliability, and validity of Disorders of Consciousness Scale. J Rehabil Res Dev 2005;42:1-17.

23. Rader MA, Ellis DW. The Sensory Stimulation Assessment Measure (SSAM): a tool for early evaluation of severely brain-injured patients. Brain Inj 1994;8:309-321.

24. Monti MM, Rosenberg M, Finoia P, Kamau E, Pickard JD, Owen AM. Thalamofrontal connectivity mediates top-down cognitive functions in disorders of consciousness. Neurology 2015;84:167-173.

25. Kotchoubey B, Yu T, Mueller F, Vogel D, Veser S, Lang S. True or false? Activations of language-related areas in patients with disorders of consciousness. Curr Pharm Des 2014;20:4239-4247.

26. Stender J, Gosseries O, Bruno MA, et al. Diagnostic precision of PET imaging and functional MRI in disorders of consciousness: a clinical validation study. Lancet 2014 384:514-522.

27. Sitt JD, King JR, El Karoui I, et al. Large scale screening of neural signatures of consciousness in patients in a vegetative or minimally conscious state. Brain 2014;137: $2258-2270$

28. Nakase-Richardson R, Whyte J, Giacino JT, et al. Longitudinal outcome of patients with disordered consciousness in the NIDRR TBI Model Systems Programs. J Neurotrauma 2012;29:59-65.

29. Katz DI, Polyak M, Coughlan D, Nichols M, Roche A. Natural history of recovery from brain injury after prolonged disorders of consciousness: outcome of patients admitted to inpatient rehabilitation with 1-4 year follow-up. Prog Brain Res 2009; 177:73-88.

30. Riganello F, Cortese MD, Dolce G, Lucca LF, Sannita WG. The autonomic system functional state predicts responsiveness in disorder of consciousness. J Neurotrauma 2015;32:1071-1077.

31. Ashwal S, Cranford R, Bernat JL, et al. Medical aspects of the persistent vegetative state: (First of two parts). N Engl J Med 1994;330:1499-1508.

32. Childs NL, Mercer WN. Brief report: late improvement in consciousness after posttraumatic vegetative state. N Engl J Med 1996;334:24-25

33. Marshall LF, Becker DP, Bowers SA, et al. The National Traumatic Coma Data Bank: part 1: design, purpose, goals, and results. J Neurosurg 1983;59:276-284.

34. Luaute J, Maucort-Boulch D, Tell L, et al. Long-term outcomes of chronic minimally conscious and vegetative states. Neurology 2010;75:246-252.

35. Estraneo A, Moretta P, Loreto V, et al. Predictors of recovery of responsiveness in prolonged anoxic vegetative state. Neurology 2013;80:464-470.

36. Estraneo A, Moretta P, Loreto V, Lanzillo B, Santoro L, Trojano L. Late recovery after traumatic, anoxic, or hemorrhagic long-lasting vegetative state. Neurology 2010;75 239-245.

37. Whyte J, Nakase-Richardson R. Disorders of consciousness: outcomes, comorbidities, and care needs. Arch Phys Med Rehabil 2013;94:1851-1854.

38. Giacino JT, Kalmar K. The vegetative and minimally conscious states: a comparison of clinical features and functional outcome. J Head Trauma Rehabil 1997;12:36-51.

39. Ganesh S, Guernon A, Chalcraft L, Harton B, Smith B, Louise-Bender Pape T. Medical comorbidities in disorders of consciousness patients and their association with functional outcomes. Arch Phys Med Rehabil 2013;94:1899-1907.

40. Nakase-Richardson R, McNamee S, Howe LL, et al. Descriptive characteristics and rehabilitation outcomes in active duty military personnel and veterans with disorders of consciousness with combat- and noncombat-related brain injury. Arch Phys Med Rehabil 2013;94:1861-1869.

\section{Are You Ready to Maximize Your Medicare Reimbursement?}

Use the AAN tools and resources to earn positive payments and avoid penalties under MIPS. Take action today, visit AAN.com/view/QPP 


\section{Neurology}

Practice guideline update recommendations summary: Disorders of consciousness:

Report of the Guideline Development, Dissemination, and Implementation

Subcommittee of the American Academy of Neurology; the American Congress of Rehabilitation Medicine; and the National Institute on Disability, Independent Living, and Rehabilitation Research

Joseph T. Giacino, Douglas I. Katz, Nicholas D. Schiff, et al.

Neurology 2018;91;450-460 Published Online before print August 8, 2018

DOI 10.1212/WNL.0000000000005926

This information is current as of August 8, 2018

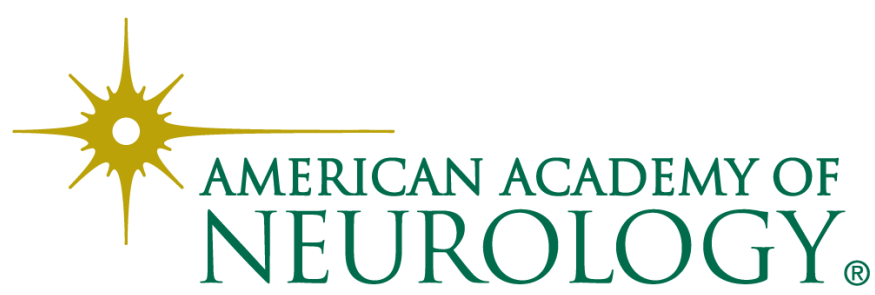




\section{Updated Information \& Services}

\section{Supplementary Material}

References

Citations

Subspecialty Collections

Errata

Permissions \& Licensing

\section{Reprints}

including high resolution figures, can be found at: http://n.neurology.org/content/91/10/450.full

Supplementary material can be found at: http://n.neurology.org/content/suppl/2018/09/10/WNL.0000000000005 926.DC1

This article cites 40 articles, 7 of which you can access for free at: http://n.neurology.org/content/91/10/450.full\#ref-list-1

This article has been cited by 12 HighWire-hosted articles: http://n.neurology.org/content/91/10/450.full\#\#otherarticles

This article, along with others on similar topics, appears in the following collection(s):

\section{All Clinical Neurology}

http://n.neurology.org/cgi/collection/all_clinical_neurology

All clinical neurophysiology

http://n.neurology.org/cgi/collection/all_clinical_neurophysiology

All Pediatric

http://n.neurology.org/cgi/collection/all_pediatric

\section{Brain trauma}

http://n.neurology.org/cgi/collection/brain_trauma

Plasticity

http://n.neurology.org/cgi/collection/plasticity

An erratum has been published regarding this article. Please see next page or:

/content/93/3/135.3.full.pdf

Information about reproducing this article in parts (figures,tables) or in its entirety can be found online at:

http://www.neurology.org/about/about_the_journal\#permissions

Information about ordering reprints can be found online:

http://n.neurology.org/subscribers/advertise

Neurology ${ }^{\circledR}$ is the official journal of the American Academy of Neurology. Published continuously since 1951, it is now a weekly with 48 issues per year. Copyright . All rights reserved. Print ISSN: 0028-3878. Online ISSN: 1526-632X.

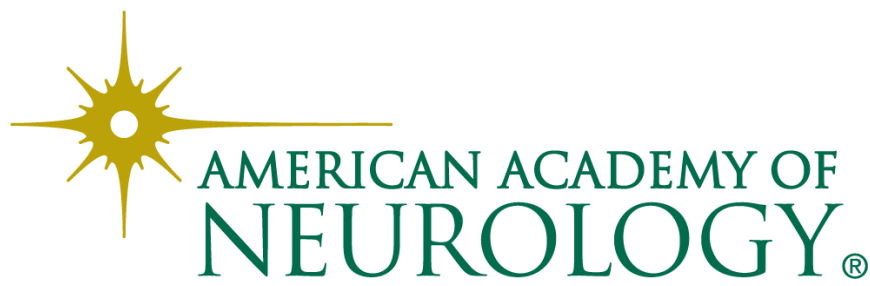




\title{
Disputes \& Debates: Editors' Choice
}

Steven Galetta, MD, FAAN, Section Editor

\section{Editors' note: Incorporating sleep medicine content into medical school through neuroscience core curricula}

In this issue of Neurology, Dr. Salas and a team of sleep medicine and medical education experts representing 6 major academic centers report on the need for and value of a formal sleep medicine curriculum in medical school. Not only are sleep medicine disorders extraordinarily common—affecting 1 in 6 Americans, according to survey data—but they are strongly tied to a swath of other comorbid conditions, ranging from cardiovascular disease to synucleinopathies. The authors also acknowledge that a heightened awareness of sleep hygiene among medical trainees may improve their own wellness and attenuate physician burnout. Dr. Sethi expresses some reservation that additional curricula may only add to the burden imposed upon medical students during their neurology clerkship. Instead, Dr. Sethi writes, perhaps sleep medicine should be incorporated into trainee education at the residency level. In response, Dr. Strowd and colleagues acknowledge this barrier. They emphasize the importance of pre-clerkship and longitudinal exposure to sleep medicine in order to crystallize these clinical concepts. By enriching the medical school curriculum with dedicated sleep medicine training, the authors hope that evaluating patients with sleep disorders will no longer be a sudden awakening.

\section{Reader response: Incorporating sleep medicine content into medical school through neuroscience core curricula}

\author{
Nitin K. Sethi (New York) \\ Neurology ${ }^{\circledR}$ 2019;93:132. doi:10.1212/WNL.0000000000007788
}

I read with interest the suggested proposal of Salas et al. ${ }^{1}$ to incorporate sleep medicine content into current medical school core curriculum. While I support the authors' recommendations, the medical school neuroscience core curriculum is already packed and students are burdened by a large number of specific learning objectives they are expected to meet by the end of their neurology clerkship. A better way to meet the growing need for sleep clinical care within the health care system would be to emphasize its education at the neurology residency level. The American Academy of Neurology Clinical Neurophysiology (CNP) Section Resident Core Curriculum $^{2}$ lists that the resident, "Be familiar with the basic principles of tests, including polysomnography, and multiple sleep latency tests, and evaluation of various sleep disorders.” In my experience, most neurology residents-during their CNP rotation-often spend time on CNP procedures, such as EEG and EMG, at the expense of sleep medicine.

1. Salas RME, Strowd RE, Ali I, et al. Incorporating sleep medicine content into medical school through neuroscience core curricula. Neurology 2018;91:597-610.

2. Westmoreland B. American Academy of Neurology Clinical Neurophysiology (CNP) Section Resident Core Curriculum. In: American Academy of Neurology: AAN Core Curricula [online]. Available at: aan.com/siteassets/home-page/tools-and-resources/academicneurologist-researchers/teaching-materials/aan-core-curricula-for-program-directorstor/clinical-neurophysiology-resident_tr.pdf. Accessed October 3, 2018.

Copyright (c) 2019 American Academy of Neurology 


\title{
Author response: Incorporating sleep medicine content into medical school through neuroscience core curricula
}

\author{
Roy E. Strowd (Winston-Salem, NC), Logan Schneider (Stanford, CA), Charlene E. Gamaldo (Baltimore), \\ and Rachel Marie E. Salas (Baltimore) \\ Neurology ${ }^{\circledR}$ 2019;93:133. doi:10.1212/WNL.0000000000007792
}

We appreciate Dr. Sethi's feedback highlighting some obstacles we considered when formulating our suggestions for integrating sleep medicine training into medical school, ${ }^{1}$ namely when and where to deliver sleep content.

We agree that more in-depth training should be provided to neurology residents, possibly as a component of their clinical neurophysiology rotations, as previously suggested. ${ }^{2}$ We also see a need for moving sleep medicine exposure earlier for all students. We agree that medical school curricula are already packed. We advocate for using evidence-based approaches that integrate clinical patient contact into preclerkship training and basic neuroscience instruction into clerkships. ${ }^{3,4}$ Preclerkship neuroscience courses should provide an entry point, teaching sleep fundamentals and providing exposure-which is currently the case of neuroscience curricula at some schools. Clerkship rotations then deepen students' application of sleep physiology to patients and focus on the clinical examination and management of sleep disorders.

Although we see neurology as an important leader in sleep medicine training, a strength of this field is the diversity of backgrounds that contribute to this area of medicine. Further integrating sleep training across these many fields during medical school and residency will likely reduce curricular burden, benefit training programs, and influence patients.

1. Salas RME, Strowd RE, Ali I, et al. Incorporating sleep medicine content into medical school through neuroscience core curricula. Neurology 2018;91:597-610.

2. Avidan AY, Vaughn BV, Silber MH. The current state of sleep medicine education in US neurology residency training programs: where do we go from here? J Clin Sleep Med 2013;9:281-286.

3. Wilkerson L, Stevens CM, Krasne S. No content without context: integrating basic, clinical, and social sciences in a pre-clerkship curriculum. Med Teach 2009;31:812-821.

4. Rajan SJ, Jacob TM, Sathyendra S. Vertical integration of basic science in final year of medical education. Int J Appl Basic Med Res 2016;6:182-185.

Copyright (c) 2019 American Academy of Neurology

\section{Editors' note: A sleep medicine medical school curriculum: Time for us to wake up}

In Dr. Smith's editorial regarding the newly suggested sleep medicine curriculum by Salas et al., the author summarizes a call to arms in order to increase trainee exposure to sleep disorders. For conditions that affect 50-70 million Americans, with tens of billions of dollars in annual healthcare costs, sleep medicine training comprises a regrettable minority of medical education $(0.06 \%$ of total classroom time). A heightened awareness of sleep disorders in medical school may also indirectly benefit medical students themselves as they reflect on their own sleep practices. With better sleep hygiene, Dr. Smith postulates, students may be at a lower risk of burnout. Dr. Spector, a sleep disorders specialist, worries that enforcement of additional coursework regarding sleep hygiene is hardly a solution to the burnout problem. Encouraging students to re-evaluate their own sleep practices by mandating additional coursework would be like "rubbing salt in a wound." Regardless of how or when formal instruction in sleep medicine is provided, everyone seems to agree that our deficiency of sleep medicine exposure should serve as a wake-up call for medical educators.

James E. Siegler III, MD, and Steven Galetta, MD

Neurology ${ }^{\circledR}$ 2019;93:133. doi:10.1212/WNL.0000000000007791 


\title{
Reader response: A sleep medicine medical school curriculum: Time for us to wake up
}

Andrew R. Spector (Durham, NC)

Neurology ${ }^{\circledR}$ 2019;93:134. doi:10.1212/WNL.0000000000007793

Dr. Smith is correct that there is an "urgent need to improve medical school sleep medicine education." I wholeheartedly agree with the proposal by Salas et al. ${ }^{2}$ Unfortunately, although there are many valid justifications for sleep medicine education, teaching about sleep will not improve burnout among medical students. The link between burnout and sleep is most likely due to sleep deprivation, ${ }^{3,4}$ but medical students are not sleep deprived because they lack the knowledge that they ought to sleep. Telling medical students to sleep more while providing no mechanism for them to do so is "rubbing salt in a wound." This could paradoxically worsen burnout by adding to the anxiety that they should be able to "do it all" - good grades, regular exercise, research, social life, and 8 hours of sleep. Sleep education will only improve students' well-being if it is coupled with substantial structural changes to the medical school experience that promote the health of the students (e.g., eliminating overnight call). Otherwise, we should promote sleep medicine education because it is important to being a well-educated physician and not because of any personal benefit for the students.

1. Smith AG. A sleep medicine medical school curriculum: time for us to wake up. Neurology 2018;91:587-588.

2. Salas RME, Strowd RE, Ali I, et al. Incorporating sleep medicine content into medical school through neuroscience core curricula. Neurology 2018;91:597-610.

3. Jarral OA, Baig K, Shetty K, Athanasiou T. Sleep deprivation leads to burnout and cardiothoracic surgeons have to deal with its consequences. Int J Cardiol 2015;179:70-72.

4. Leonard C, Fanning N, Attwood J, Buckley M. The effect of fatigue, sleep deprivation and onerous working hours on the physical and mental wellbeing of pre-registration house officers. Ir J Med Sci 1998;167:22-25.

Copyright (c) 2019 American Academy of Neurology

\section{Author response: A sleep medicine medical school curriculum: Time for us to wake up}

\author{
A. Gordon Smith (Richmond) \\ Neurology ${ }^{\circledR}$ 2019;93:134. doi:10.1212/WNL.0000000000007794
}

Dr. Spector raises an important point regarding sleep health and medical student wellness in response to my editorial. ${ }^{1}$ Addressing physician and medical student well-being will, indeed, require both structural and cultural changes in the practice of medicine. Neurology, as a specialty (largely through the efforts of the American Academy of Neurology), has established itself as a leader in addressing physician burnout. This level of professional advocacy is made possible by neurologists' recognition of this issue as a priority and their understanding of its drivers. Educating medical students about sleep health will not only prepare them to directly serve their patients' needs but will also equip them to care for themselves throughout their professional careers and to advocate for necessary reforms.

1. Smith AG. A sleep medicine medical school curriculum: time for us to wake up. Neurology 2018;91:587-588.

Copyright $\odot 2019$ American Academy of Neurology

Author disclosures are available upon request (journal@neurology.org). 


\section{Clinical phenotype, atrophy, and small vessel disease in APOE\&2 carriers with Alzheimer disease}

Neurology ${ }^{\circledR}$ 2019;93:135. doi:10.1212/WNL.0000000000007421

In the article "Clinical phenotype, atrophy, and small vessel disease in APOE\&2 carriers with Alzheimer disease" by Groot et al., ${ }^{1}$ published online ahead of print on October 19, 2018, there were errors in figure 1 and figure 5A. Figure 1 and figure 5A should each appear with axis labels. The corrected figures appear in the November 13 issue. The authors regret the error.

\section{Reference}

1. Groot C, Sudre CH, Barkhof F, et al. Clinical phenotype, atrophy, and small vessel disease in APOE\&2 carriers with Alzheimer disease. Neurology 2018;91:e1851-e1859.

\section{Core curriculum guidelines for a required clinical neurology experience}

Neurology ${ }^{\circledR}$ 2019;93:135. doi:10.1212/WNL.0000000000007481

In the article "Core curriculum guidelines for a required clinical neurology experience" by Safdieh et al., ${ }^{1}$ first published online February 22, 2019, the American Academy of Neurology Undergraduate Education Subcommittee and Consortium of Neurology Clerkship Directors should have been listed as endorsing the paper in a footnote and not listed in the author byline. The corrected version appears in the March 26 issue. The editorial office regrets the error.

\section{Reference}

1. Safdieh JE, Govindarajan R, Gelb DJ, Odia Y, Soni M. Core curriculum guidelines for a required clinical neurology experience. Neurology 2019;92:619-626.

\section{Practice guideline update recommendations summary: Disorders of consciousness}

Report of the Guideline Development, Dissemination, and Implementation Subcommittee of the American Academy of Neurology; the American Congress of Rehabilitation Medicine; and the National Institute on Disability, Independent Living, and Rehabilitation Research

Neurology ${ }^{\circledR} 2019 ; 93: 135$. doi:10.1212/WNL.0000000000007382

In the print version of the AAN Practice Guideline "Practice guideline update recommendations summary: Disorders of consciousness" by Giacino et al. ${ }^{1}$ published on September 4, 2018, the copyright line stating "Copyright (C) 2018 American Academy of Neurology" was included in error. The AAN does not claim copyright because the guideline was codeveloped by a US government agency. The corrected version was posted online on September 4, 2018. The publisher regrets the error.

\section{Reference}

1. Giacino JT, Katz DI, Schiff ND, et al. Practice guideline update recommendations summary: Disorders of consciousness: report of the Guideline Development, Dissemination, and Implementation Subcommittee of the American Academy of Neurology; the American Congress of Rehabilitation Medicine; and the National Institute on Disability, Independent Living, and Rehabilitation Research. Neurology 2018;91:450-460. 